\title{
Aortic valve replacement via right anterior thoracotomy with sutureless valves: The way to go!
}

\author{
Malakh Shrestha, MBBS, PhD
}

\author{
From the Department of Cardiothoracic, Transplantation and Vascular Surgery, Hannover Medical School, \\ Hannover, Germany. \\ Disclosures: Author has nothing to disclose with regard to commercial support. \\ Received for publication July 31, 2016; accepted for publication Aug 1, 2016. \\ Address for reprints: Malakh Shrestha, MBBS, PhD, Department of Cardiothoracic, Transplantation and Vascular \\ Surgery, Hannover Medical School, Carl-Neuberg Strasse 1, 30625 Hannover, Germany (E-mail: shrestha. \\ malakh.lal@mh-hannover.de). \\ J Thorac Cardiovasc Surg 2016;152:1547-8 \\ $0022-5223 / \$ 36.00$ \\ Copyright (c) 2016 by The American Association for Thoracic Surgery \\ http://dx.doi.org/10.1016/j.jtcvs.2016.08.003
}

In their article in this issue of the Journal, Murzi and colleagues $^{1}$ have retrospectively evaluated the outcomes of 300 consecutive patients (aged $76 \pm 6$ years) after aortic valve replacement (AVR) through a right minithoracotomy with a sutureless aortic valve prosthesis between 2011 and 2015. Learning curve was analyzed by dividing the study populations into 3 tertiles of 100 patients each. The overall mortality was $0.7 \%$. They observed no significant differences in mortality and complications among the 3 tertiles.

Murzi and colleagues ${ }^{1}$ conclude that sutureless AVR through a right minithoracotomy can be performed safely without a significant learning curve. They also conclude that with adequate training and supervision, the procedure can be spread to all the surgical staff.

Changing population demographic profiles have resulted in the increasing age of the patients presenting for AVR. The situation is similar in other industrialized countries. New techniques avoiding long extracorporeal circulation and cardiac ischemic times, as well as minimally invasive surgical access, should therefore be helpful to optimize the challenge of this changing patient cohort.

Several studies have shown that patients undergoing minimally invasive AVR have a shorter hospital stay, less pain, shorter duration of ventilation, less blood loss, and less blood transfusion than do patients undergoing conventional full sternotomy. ${ }^{2}$ Postoperatively, the patients can be mobilized earlier and the respiratory function may also be better. Limited exposure of the operative field is a disadvantage for the surgeon, and this is reflected in a longer operative time in minimally invasive cases compared with operations conducted through a full sternotomy. Furthermore, minimally invasive AVR is technically even more difficult in patients with small and calcified aortic roots. This could be one of the reasons that minimally invasive AVR is not yet being universally performed.

In the past few years, transcatheter aortic valve implantation has been proposed for elderly patients and others at reproducible.

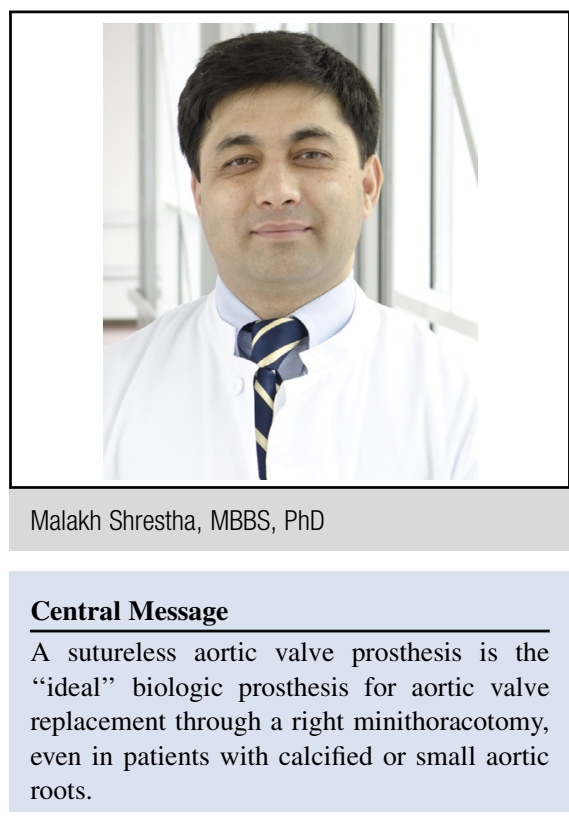

See Article page 1537.

high risk who would not qualify for conventional aortic valve operations. ${ }^{3}$ Transcatheter aortic valve implantation is still being reserved, however, for patients who either are at very high risk or are not considered suitable candidates for classic surgery.

In the study of Murzi and colleagues, ${ }^{1}$ a self-anchoring aortic valve was implanted through a right minithoracotomy. The proposed advantages of self-anchoring prostheses are as follows:

1. Absence of the need for anchoring sutures potentially reduces the cardiac ischemic (crossclamp) time and consequently extracorporeal circulation time.

2. Self-anchoring valve designs eliminate the need for suturing ring present in conventional prostheses, resulting in increased functional valvular diameter.

3. Absence of the need for sutures makes minimally invasive access technically easier and thus also more

In this study, Murzi and colleagues ${ }^{1}$ indeed observed that limited exposure in minimally invasive access not a disadvantage. Conversion to full sternotomy was rarely required. Nevertheless, one of their conclusions, that "sutureless AVR via a right minithoracotomy can be performed without a significant learning curve," must be 
qualified. Murzi and colleagues ${ }^{1}$ state that they were already performing AVR through a right minithoracotomy with conventional valves. The chief surgeon already had a large experience in AVR through a right minithoracotomy. Only 3 surgeons had not personally performed AVR through a right minithoracotomy, and they had certainly assisted in such cases. ${ }^{4}$ Obviously, changing to a sutureless valve prosthesis made the valve implantation "technically easier" and may have contributed to the absence of the learning curve. As Murzi and colleagues ${ }^{1}$ point out, it is mandatory that the surgical training be structured and closely monitored. The surgeons need to be trained separately in AVR through a right minithoracotomy and in sutureless AVR. My own institution's experience with sutureless valves, starting from the "first in human" implantation in April 2007, has been similar. ${ }^{5-7}$

In summary, this study highlights the advantages of the Perceval S sutureless valve (LivaNova PLC, London, UK). It is a technically simple and "ideal" biologic prosthesis for AVR through a right minithoracotomy, even in patients with calcified or small aortic roots. In this respect, Murzi and colleagues ${ }^{1}$ are to be congratulated for this interesting article and will help in enabling broader application of minimally invasive AVR.

\section{References}

1. Murzi M, Cerillo AG, Gilmanov D, Concistrè G, Farneti P, Glauber M, et al. Exploring the learning curve for minimally invasive sutureless aortic valve replacement. J Thorac Cardiovasc Surg. 2016;152:1537-46.e1.

2. Tabata M, Umakanthan R, Cohn LH, Bolman RM III, Shekar PS, Chen FY, et al. Early and late outcomes of 1000 minimally invasive aortic valve operations. Eur J Cardiothorac Surg. 2008;33:537-41.

3. Cribier A, Eltchaninoff $\mathrm{H}$, Bash A, Borenstein N, Tron C, Bauer F, et al. Percutaneous transcatheter implantation of an aortic valve prosthesis for calcific aortic stenosis: first human case description. Circulation. 2002;106:3006-8.

4. Gilmanov D, Miceli A, Ferrarini M, Farneti P, Murzi M, Solinas M, et al. Aortic valve replacement through right anterior minithoracotomy: can sutureless technology improve clinical outcomes? Ann Thorac Surg. 2014;98:1585-92.

5. Shrestha M, Khaladj N, Bara C, Hoeffler K, Hagl C, Haverich A. A staged approach towards interventional aortic valve implantation with a sutureless valve: initial human implants. Thorac Cardiovasc Surg. 2008;56:398-400.

6. Shrestha M, Timm R, Höffler K, Koigeldiyev N, Khaladj N, Hagl C, et al. Minimally invasive aortic valve replacement with self-anchoring Perceval valve. J Heart Valve Dis. 2013;22:230-5.

7. Shrestha M, Maeding I, Höffler K, Koigeldiyev N, Marsch G, Siemeni T, et al. Aortic valve replacement in geriatric patients with small aortic roots: are sutureless valves the future? Interact Cardiovasc Thorac Surg. 2013;17:778-82; discussion 782. 